\title{
Geographic Information System Tools for Conservation Planning
}

\section{History}

Conservation planning is a high priority for many Federal agencies. The U.S. Fish and Wildlife Service (FWS) is currently developing Comprehensive Conservation Plans (CCP) for all National Wildlife Refuges, the National Park Service is developing Inventory and Monitoring Networks for all Parks, and the National Forest Service continually revises forest management plans. These agencies are charged with providing for wildlife and habitat concerns and need ways to incorporate landscape, species, and habitat relations into their conservation planning. Computerized decision support systems (DSS) provide a means for organizing existing geographical, physical, and biological data for better management of natural resources.

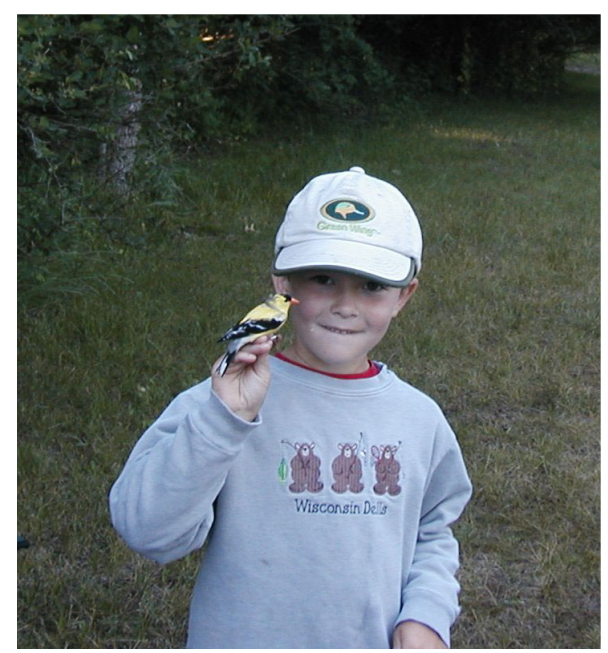

Decision support tools help managers protect bird populations for the enjoyment of future generations.

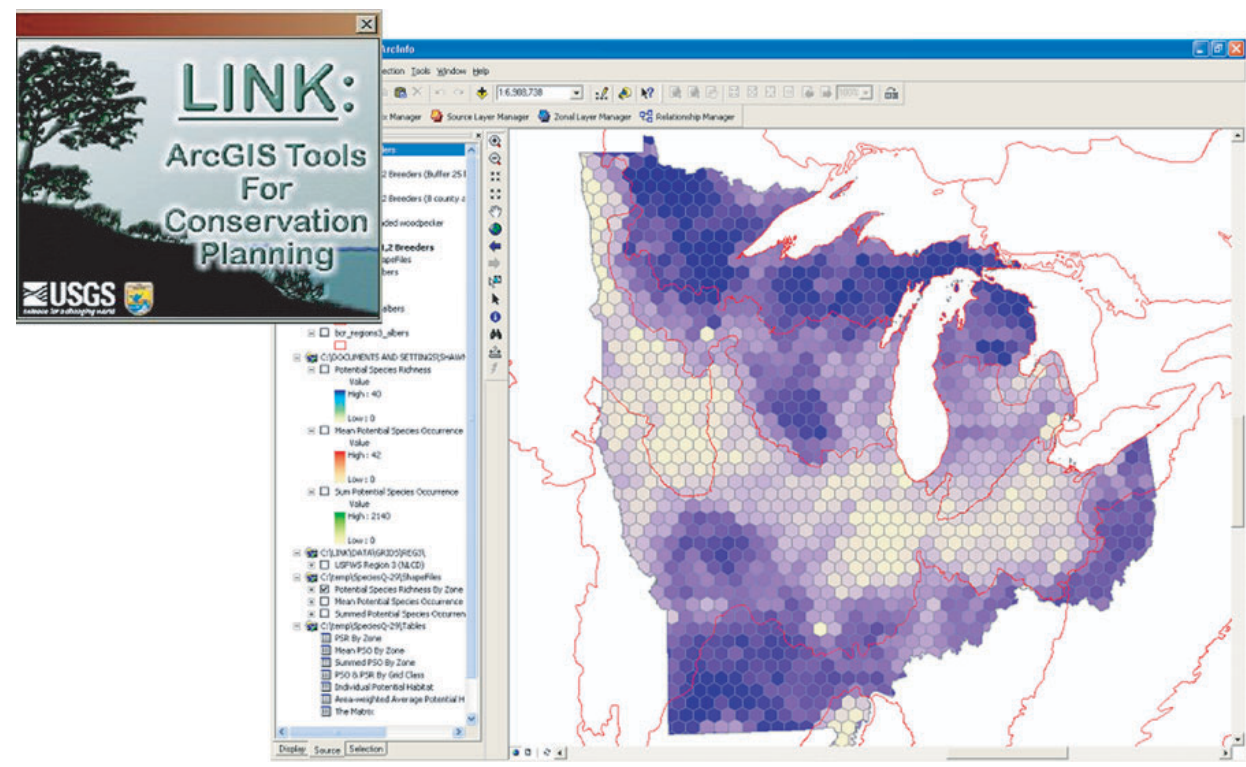

Zone map produced by the decision support system tool showing areas of high potential species richness for birds of high conservation concern in U.S. Fish and Wildlife Service Region 3.

\section{What USGS has done}

For over a decade, the USGS Upper Midwest Environmental Sciences Center (UMESC) has been developing DSS tools for conservation planning: (http:// www.umesc.usgs.gov/dss.html) Recently, UMESC has focused on the development of geographic information systems DSS tools to assist FWS regional refuge planners and refuge staff in the $\mathrm{CCP}$ process for lands managed by the FWS. These tools allow you to rapidly determine characteristics of the landscape based on presumed relations between species and habitats. You can summarize in tables, charts, and maps and include measures of potential species occurrence, potential species richness, and the area and proportion of land cover types. The tools can calculate results for areas ranging from small local management units to large states or Bird Conservation Regions. The tools also allow managers to compare the conservation potential of local management units with that of the surrounding county, state, or ecoregion.

The newest conservation planning tool is available on the Internet and is designed to summarize land cover and bird survey data across the continental United States. An interactive map allows users to visualize and download land uses for counties and bird counts obtained through the North American Breeding Bird Survey (BBS) for areas such as Federal lands, counties, states, and other geographic divisions. A visitor to the Web site can select a 


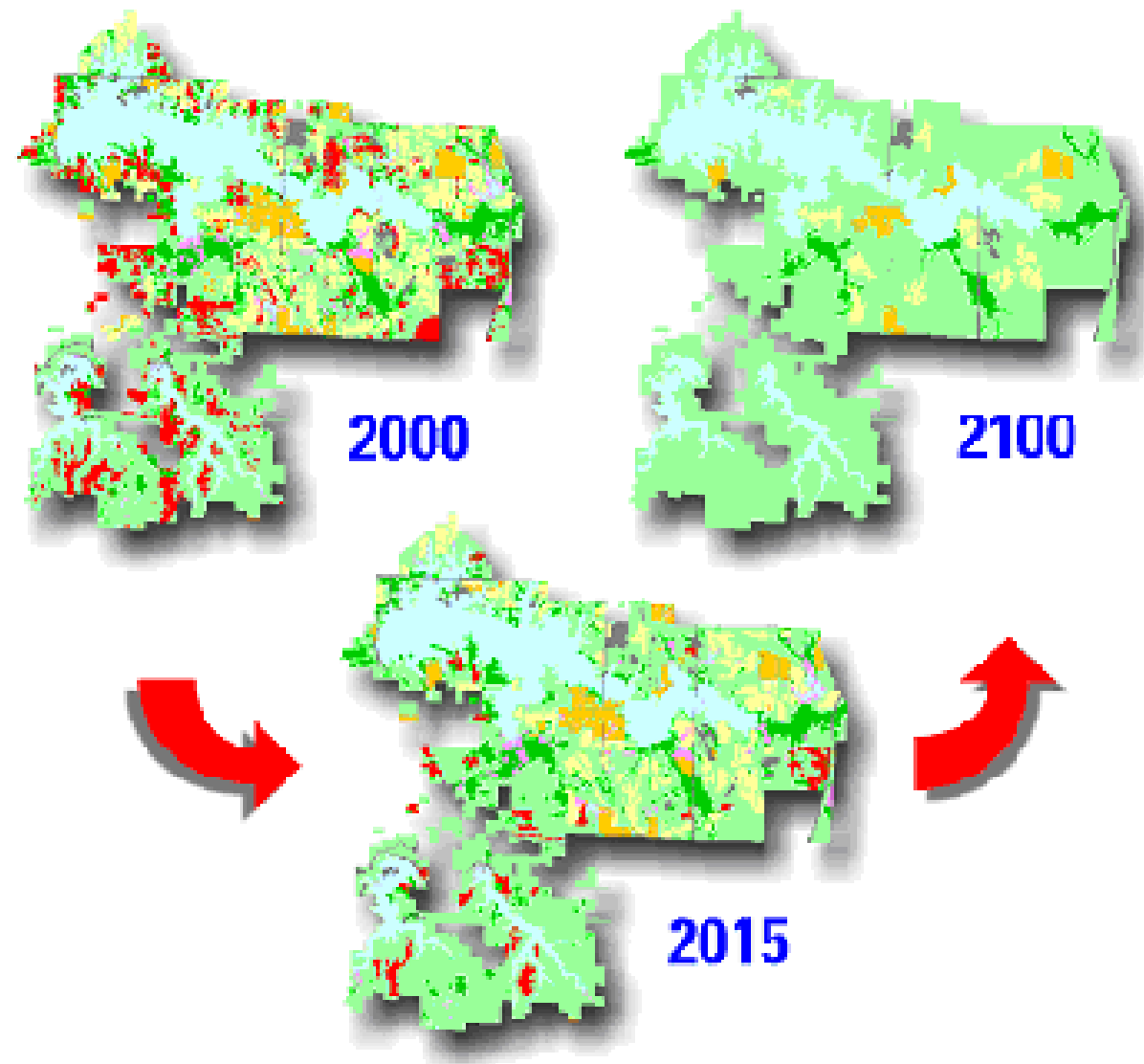

Land cover maps representing different types of wildlife habitat at Crab Orchard National Wildlife Refuge are shown above. These maps represent current conditions and projected future conditions based on a set of targeted management plans.

specific location and calculate the number of bird species observed on BBS routes near the selected location. For instance, you can obtain information on the amount of forest within a county and the number of golden-winged warblers counted by the BBS within or near the county. The UMESC now has a set of DSS planning tools that will improve the objectivity of conservation planning at geographic scales ranging from local to continental.

\section{Result}

The conservation planning tools described above have been used by Federal and state managers responsible for natural resources as diverse as the Upper Mississippi River System, the Columbia River, the St. Croix National Scenic Riverway, the Great Lakes, Acadia National Park, the Everglades ecosystem, and several FWS refuges. need of management action. These tools allow managers to review a set of alternative management actions and quantify or visualize the effects of these actions on species of conservation concern. The tools are especially useful if stakeholders disagree about the benefits of alternative management scenarios. Maps, tables, and charts help explain to the public the predicted consequences of alternative management actions.

\section{For more information, contact}

\author{
Melinda Knutson \\ 608.781.6339 \\ mknutson@usgs.gov
}

or

\section{Jason Rohweder}

608.781.6228

jrohweder@usgs.gov

USGS Upper Midwest Environmental Sciences Center

2630 Fanta Reed Road

La Crosse, WI 54603

http://www.umesc.usgs.gov/

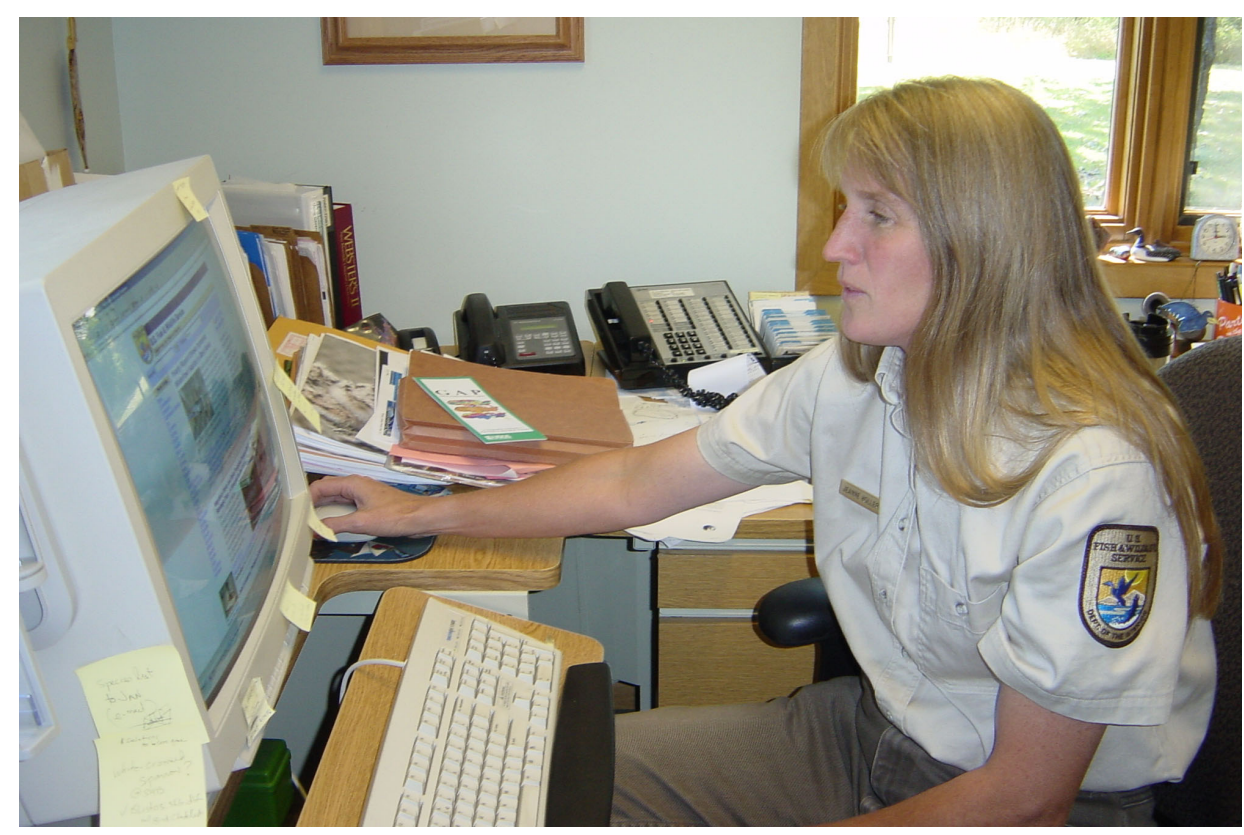

Management agencies such as the U.S. Fish and Wildlife Service use decision support system tools to set priorities for management. 